\title{
Acute respiratory distress syndrome after cardiac surgery
}

\author{
Lisa Q. Rong', Antonino Di Franco ${ }^{2}$, Mario Gaudino ${ }^{2}$ \\ ${ }^{1}$ Department of Anesthesiology, ${ }^{2}$ Department of Cardio-Thoracic Surgery, Weill Cornell Medicine, New York, NY, USA \\ Contributions: (I) Conception and design: M Gaudino; (II) Administrative support: None; (III) Provision of study materials: A Di Franco; (IV) \\ Collection and assembly of data: A Di Franco; (V) Data analysis and interpretation: LQ Rong, A Di Franco, M Gaudino; (VI) Manuscript writing: \\ All authors; (VII) Final approval of manuscript: All authors. \\ Correspondence to: Mario Gaudino, MD. Department of Cardio-Thoracic Surgery, Weill Cornell Medicine, 525 E 68th St, New York, NY 10065, \\ USA. Email: mfg9004@med.cornell.edu.
}

\begin{abstract}
Acute respiratory distress syndrome (ARDS) is a leading cause of postoperative respiratory failure, with a mortality rate approaching $40 \%$ in the general population and $80 \%$ in the subset of patients undergoing cardiac surgery. The increased risk of ARDS in these patients has traditionally been associated with the use of cardiopulmonary bypass (CPB), the need for blood product transfusions, large volume shifts, mechanical ventilation and direct surgical insult. Indeed, the impact of ARDS in the cardiac population is substantial, affecting not only survival but also in-hospital length of stay and long-term physical and psychological morbidity. No patient undergoing cardiac surgery can be considered ARDS risk-free. Early identification of those at higher risk is crucial to warrant the adoption of both surgical and non-surgical specific preventative strategies. The present review focuses on epidemiology, risk assessment, pathophysiology, prevention and management of ARDS in the specific setting of patients undergoing cardiac surgery.
\end{abstract}

Keywords: Acute respiratory distress syndrome (ARDS); respiratory failure; cardiac surgery

Submitted Sep 20, 2016. Accepted for publication Sep 30, 2016.

doi: $10.21037 /$ jtd.2016.10.74

View this article at: http://dx.doi.org/10.21037/jtd.2016.10.74

\section{Introduction}

First described in 1967 by Ashbaugh et al. (1) acute respiratory distress syndrome (ARDS) is recognized as a leading cause of postoperative respiratory failure, associated with a mortality rate approaching $40 \%$ in the general population and $80 \%$ in the subset of patients undergoing cardiac surgery $(2,3)$. In this specific cohort, the incidence of ARDS ranges from $0.4 \%$ to $20 \%$ (4-10) with high variability attributable to differences in design methodology of the studies, study populations and different ARDS definitions. Taking into account the fact that worldwide $>800,000$ patients per year undergo coronary artery bypass grafting (CABG) surgery and approximately 150,000 patients undergo valve surgery $(11,12)$, ARDS undoubtedly represents a significant concern with profound economic implications.

Over years, several descriptions have been proposed until the American-European Consensus Conference (AECC) definition was published in 1994 (13). Although its adoption has allowed for remarkable epidemiological and clinical gain, issues regarding its reliability and validity have emerged. In order to address the limitations of the AECC definition, the Berlin Definition of ARDS was published in 2012 (14). Accordingly, ARDS is now defined as hypoxemia occurring within 1 week of a known clinical insult or new worsening respiratory symptoms, associated with bilateral opacities on chest imaging not fully explained by effusions and lobar/lung collapse or nodules, and not fully explained by cardiac failure or fluid overload. The often misinterpreted term "acute lung injury" (ALI) previously used in the AECC definition has been removed and only three mutually exclusive subgroups of ARDS are now described:

* Mild ARDS: $200 \mathrm{mmHg}<\mathrm{PaO}_{2} / \mathrm{FiO}_{2} \leq 300 \mathrm{mmHg}$ with positive end-expiratory pressure (PEEP) or continuous positive airway pressure $\geq 5 \mathrm{cmH}_{2} \mathrm{O}$;

- Moderate ARDS: $100 \mathrm{mmHg}<\mathrm{PaO}_{2} / \mathrm{FiO}_{2} \leq 200 \mathrm{mmHg}$ with $\mathrm{PEEP} \geq 5 \mathrm{cmH}_{2} \mathrm{O}$; 
Table 1 Risk factors for the development of ARDS in cardiac surgery patients

\begin{tabular}{ll}
\hline Reference & Risk factors \\
\hline Asimakopoulos et al. (4) & Poor LVEF; NYHA II-IV \\
Chen et al. (18) & Age; liver cirrhosis; massive blood transfusions; tricuspid valve replacement \\
Christenson et al. (16) & Post-operative low cardiac output; current smoking; LVEF <40\%; hypovolemic hypotension; \\
& NYHA III-IV; hypertension; combined cardiac procedure; emergency procedure \\
Kaul et al. (17) & Recent smoking; advanced COPD; emergency CABG \\
Kogan et al. (15) & Previous cardiac surgery; complex cardiac surgery; more than 3 transfusions with packed \\
& red blood cells \\
Milot et al. (9) & Previous cardiac surgery; shock; multiple transfusions \\
\hline
\end{tabular}

ARDS, acute respiratory distress syndrome; LVEF, left ventricular ejection fraction; NYHA, New York Heart Association; COPD, chronic obstructive pulmonary disease; CABG, coronary artery bypass grafting.

* Severe ARDS: $\mathrm{PaO}_{2} / \mathrm{FiO}_{2} \leq 100 \mathrm{mmHg}$ with PEEP $\geq 5 \mathrm{cmH}_{2} \mathrm{O}$.

The increased risk of ARDS following cardiac surgery has been associated with the use of cardiopulmonary bypass $(\mathrm{CPB})$, the need for blood product transfusions, large volume shifts, mechanical ventilation and direct surgical insult. Indeed, the impact of ARDS in the cardiac population is substantial, affecting not only survival but also in-hospital length of stay and long-term physical and psychological morbidity (15).

\section{ARDS risk assessment in cardiac surgery}

No patient undergoing cardiac surgery can be considered ARDS risk-free. Early identification of those at higher risk is crucial to warrant the adoption of specific preventative strategies.

Conflicting evidence about risk factors has been produced and general agreement is lacking. Post-operative low cardiac output, current smoking, left ventricular ejection fraction (LVEF) $<40 \%$, hypovolemic hypotension, New York Heart Association (NYHA) class III-IV, hypertension, combined cardiac procedures and emergency operation were proposed by Christenson et al. (16). Kaul and colleagues only found recent smoking, advanced chronic obstructive pulmonary disease (COPD) and emergency CABG to be associated with the development of the disease (17) while other authors only reported poor LVEF and NYHA class III-IV as risk factors (4). Previous cardiac surgery, shock and multiple transfusions were depicted as predictors of ARDS by Milot et al. (9). Previous cardiac surgery, complex cardiac surgery and more than three transfusions with packed red blood cells were identified by Kogan and colleagues (15). Age, liver cirrhosis, massive blood transfusions and tricuspid valve replacement were recently reported as independent risk factors for ARDS in the particular subset of patients undergoing valvular surgery (18) (see Table 1).

Several standardized risk scores to be used in cardiac surgery patients have been proposed, including the European System for Cardiac Operative Risk Evaluation (EuroScore) and the Society of Thoracic Surgeons (STS) Score. Recently, a new score (the "Surgical Lung Injury Prediction score 2", SLIP-2) has been developed by Kor et al. (7) to help identify surgical patients at risk for ARDS, based on the presence of nine independent predictors of ARDS [sepsis, high-risk aortic vascular surgery, high-risk cardiac surgery, emergency surgery, cirrhosis, admission location other than home, increased respiratory rate (20-29 and $>30$ breaths/min), $\mathrm{FiO}_{2}$ greater than $35 \%$, and $\mathrm{SpO}_{2}$ less than $95 \%]$.

\section{Type of surgical procedure and risk of pulmonary complications}

While cardiac surgery is in general recognized as a risk factor for developing ARDS, not all cardiac surgical procedures carry the same level of risk. A generic 10\% risk of ARDS after cardiac surgery has been demonstrated by Gajic et al. (6) who also showed that this might increase up to $16 \%$ in the particular setting of aortic surgery. In the case of emergent procedures for aortic catastrophes, the risk of respiratory 
failure may instead be as high as 50\% (19). The incidence of ARDS according to the recent Berlin Definition was found to be $8.1 \%$ after valve surgery (18); interestingly, tricuspid valve replacement was determined as an independent risk factor for ARDS (OR 5.197; 95\% CI: 1.428-18.914; $\mathrm{P}=0.012$ ). Rates of respiratory failure higher than $20 \%$ have also been documented after left ventricular assist device placement, although not all of the cases may be strictly linked to ARDS (20). The impact of redo cardiac surgery as a risk factor for developing ARDS has been elegantly investigated by Milot et al. (9) who hypothesized a possible causative role of prior protamine sensitization, triggering a severe immune reaction at the end of $\mathrm{CPB}$ with protamineheparin complexes leading to the release of $\mathrm{C} 3 \mathrm{a}$ and $\mathrm{C} 4 \mathrm{a}$. Of note, an immune reaction to protamine might be also due to IgE-mediated anaphylaxis, complement-mediated anaphylactoid reactions caused by heparin-protamine complexes or protamine-antiprotamine complexes or direct toxicity (21-23).

\section{Pathophysiology of ARDS after cardiac surgery}

\section{$C P B$ and $A R D S$}

It has been speculated that the exposure of blood to abnormal surfaces and abnormal conditions, as in the case of $\mathrm{CPB}$, may elicit a systemic inflammatory response that could, at least in part, explain the onset of ARDS in patients undergoing cardiac surgery (24).

The pathophysiology of ARDS following CPB has not been completely defined yet. Nevertheless, complement activation through the alternative pathway during the initial phase of $\mathrm{CPB}$ and the concurrent release of $\mathrm{C} 3 \mathrm{a}$ and $\mathrm{C} 5 \mathrm{a}$ seem to have a central role (25), being able to cause an accumulation of activated neutrophils in the pulmonary circulation and subsequent release of lysosomal granular contents (such as elastase and myeloperoxidase), leading to diffuse pulmonary injury (9). This process can be furthermore amplified by low cardiac output, splanchnic hypoperfusion and transient gut mucosal ischemia causing bacterial endotoxin translocation (26,27). Notably, heparin administered during CPB needs to be neutralized at the end of the procedure by the use of protamine which is known to be able to activate the classical complement pathway (21). However, this inflammatory response is usually well tolerated by the majority of patients and additional explanation must be sought. Recently, an association between interleukin (IL)-18 and IL-6 gene polymorphism and a susceptibility to the development of lung injury after CPB have been demonstrated $(28,29)$, suggesting a possible clinical significance of pro-inflammatory and anti-inflammatory imbalance in determining ARDS after CPB.

\section{Blood transfusions and ARDS}

Patients undergoing cardiac surgery are among those who most frequently require blood and blood product transfusion.

The association between blood transfusion and pulmonary complication has extensively been documented $(30,31)$ although a complete understanding of transfusionrelated acute lung injury (TRALI) is missing. TRALI is defined as the occurrence of hypoxia and bilateral pulmonary infiltrates within 6 hours of a transfusion, usually presenting with tachypnea, cyanosis, dyspnea and fever (32). Its prevalence among cardiac surgical patients has been estimated to be $2.4 \%$ (33) with mortality ranging from $5 \%$ to $25 \%$ (10).

The etiopathology of TRALI is certainly complex. A two-event hypothesis has been postulated, the "first event" being an underlying inflammatory condition causing priming of the pulmonary neutrophils and the "second event" being represented by the transfusion of blood products, containing either antibodies or factors that accumulate during storage and provide additional signals for neutrophil-mediated endothelial damage, increased permeability and, eventually, lung injury $(34,35)$. As reported by Vlaar et al. (36) in a study involving 668 patients, cardiac surgery is itself associated with the onset of systemic inflammation, as demonstrated by an increase in plasma levels of IL-6, IL- 8 and elastase- $\alpha 1$-antitripsin complexes after surgery compared with pre-surgery levels $(\mathrm{P}<0.001)$. Notably, CPB involves extra-corporeal blood transport through tubing whose surfaces are known to prime neutrophils and decrease pulmonary transit as they become elongated and lose their deformability (37): priming of neutrophils occurring during surgery and CPB may, therefore, represent the "first hit" in TRALI. Their activation following the infusion of antibodies or supernatant of stored plasma from blood product concentrates may instead serve as a "second hit" (38).

Blood transfusion in itself might be considered a risk factor for pulmonary complications independent of TRALI. Koch and colleagues (39) examined pulmonary morbidity related to transfusion both intraoperatively and 
postoperatively in a large cohort of patients undergoing cardiac surgery with use of $\mathrm{CPB}$ (16,847 patients). Patients receiving red blood cells transfusion had more risk-adjusted pulmonary complications: respiratory distress (4.8\% vs. $1.5 \%$; $\mathrm{P}<0.001)$, respiratory failure $(2.2 \%$ vs. $0.39 \% ; \mathrm{P}<0.0001)$, longer intubation times (9.9 vs. 7.5 hours; $\mathrm{P}<0.0001$ ), ARDS (0.64\% vs. $0.21 \% ; \mathrm{P}=0.015)$ and reintubation $(5.6 \%$ vs. $1.3 \% ; \mathrm{P}<0.0001)$. Fresh frozen plasma was similarly related to more pulmonary complications after surgery. By TRALI criteria, the majority manifested "lung injury" $\left(\mathrm{PaO}_{2} / \mathrm{FiO}_{2}\right.$ ratio $<300)$ but unrelated to transfusion $(65 \%$ vs. $64 \%)$. The authors conclude that cardiac surgical patients with poor cardiopulmonary reserve who received transfusion had more risk adjusted pulmonary morbidity after surgery. Whether increased pulmonary morbidity was related to TRALI, transfusion-associated circulatory overload or both, is uncertain in part because of current consensus-criteria for TRALI are insufficient for the cardiac surgical population. Almost 80,000 units of blood products were transfused in the subset of cardiac surgical patients in a period of less than 10 years: according to current prevalence estimates, TRALI could have been identifiable in approximately 72 patients. Of note, the current Berlin definition of ARDS was not available at the time the study was conducted.

\section{Prevention and management of ARDS in the setting of cardiac surgery}

\section{Preventive measures}

As observed by García-Delgado et al. (40) at any rate, strategies that are recommended to limit the effect of $\mathrm{CPB}$ on lung injury should include a reduction in $\mathrm{CPB}$ duration or the use of off-pump CABG, heparin-coated circuits, leucocyte depletion or intra-operative ultrafiltration. Since safety of restricted hemoglobin target $(7-8 \mathrm{mg} / \mathrm{dL})$ has been proved (41), minimization of blood product administration should be pursued to decrease the risk of TRALI.

Overall, prevention of ARDS should include both surgical and non-surgical techniques.

\section{Surgical techniques}

Studies on the effect of off-pump coronary artery bypass $(\mathrm{OPCAB})$ on lung function in low-risk patients have failed to show a benefit over on-pump surgery $(42,43)$ while more promising results have been obtained in patients with existing lung disease, elderly and high-risk patients. Meharwal et al. (44) compared 1,075 high risk, older than 70 years patients undergoing OPCAB with 2,312 patients undergoing on-pump surgery. Both intubation time and incidence of prolonged postoperative ventilation (defined as greater than 48 hours) were significantly lower in the OPCAB group $(\mathrm{P}<0.001$ and $\mathrm{P}=0.002$, respectively). Chronic lung disease has also been shown to be associated with a greater incidence of prolonged ventilation, pneumonia, and mortality (45). Kerendi et al. (45) demonstrated that patients with chronic lung disease who undergo off-pump surgery may have significantly better outcomes when compared with those undergoing on-pump surgery. Nevertheless, not all the authors agree on the beneficial effects of OPCAB (46) and its advantages over $\mathrm{CPB}$ remain controversial. Staton et al. (47) compared pulmonary outcomes after OPCAB (100 patients) vs. on-pump CABG with CPB (97 patients). Compared to $\mathrm{CABG} / \mathrm{CPB}$, OPCAB was associated with a greater reduction in postoperative respiratory compliance $\left(-15.4 \pm 10.7\right.$ vs. $\left.-11.2 \pm 10.1 \mathrm{~mL} / \mathrm{cmH}_{2} \mathrm{O} ; \mathrm{P}=0.007\right)$ associated with increased fluid administration and rotation of the heart into the right chest to perform posterolateral grafts $(\mathrm{P}<0.001)$. Despite that, OPCAB yielded better gas exchange $(\mathrm{P}=0.001)$ and earlier extubation $(\mathrm{P}=0.001)$ but no differences in chest radiographs, spirometry, or rates of death, pneumonia, pleural effusion, or pulmonary edema.

$\mathrm{Oz}$ et al. (48) evaluated the effect of preserved pleural integrity on postoperative pain and respiratory functional status in 240 patients undergoing on-pump CABG. Both postoperative bleeding and the in-hospital stay were markedly higher in the opened pleura group than in the closed pleura group. Also, the incidence of atelectasis and pleural effusion were significantly higher in the opened pleura $(\mathrm{P}<0.01)$ while respiratory functions and postoperative pain scores were better in the closed pleura group $(\mathrm{P}<0.01$ and $\mathrm{P}=0.008$, respectively).

As reviewed by Ubben (49), only limited clinical data are available about sternotomy, the subsequent alteration of chest wall mechanics and their consequences on respiratory function. Moreover, the choice of surgical instruments may also have an impact as demonstrated by Kristjánsdóttir et al. (50) who found that using an internal mammary artery retractor in addition to a median retractor is related to reduced lung volume even three months after surgery compared with patients in whom only a median retractor was used. 


\section{Non-surgical techniques}

In attempt to reduce the systemic inflammatory response after coronary operations with $\mathrm{CPB}$, the use of intraoperative cell saver has been tested. Blood collected by the pericardial suction as well as blood remaining in the $\mathrm{CPB}$ circuit after its use might, in fact, be cleared of inflammatory cells and mediators before re-transfusion. This might, in turn, have the potential to reduce the systemic load of inflammatory cytokines on the patient. Cell saver has been demonstrated to reduce the systemic levels of the pro-inflammatory markers IL- 6 and IL- 8 at 6 hours after CPB $(\mathrm{P}<0.05)$. No significant differences were found at 24 and 72 hours between the cell saver group and the control group (51).

The effects of leukocyte filtration in cardiac surgery are debated. Small improvements in early post-operative lung function in patients receiving systemic leukodepletion have been reported; however, it did not lead to reduced hospital stay or decreased mortality (52). There is substantial evidence that cardioplegic leukocyte filtration attenuates the reperfusion injury at a cellular level, but this did not translate into clinical improvements. Finally, while various strategies involving multiple leukocyte filters, or the incorporation of pharmacological agents into leukocytedepleting protocols have been evaluated, the current available results are not conclusive (52).

The potential benefit of ultrafiltration in patients undergoing cardiac surgery was reviewed by Young and colleagues (53). It is not clear whether the reduction in proinflammatory cytokines might be of clinical significance. Zero-balance ultrafiltration (Z-BUF) is a technique whereby blood is filtered and an equal volume of crystalloid or colloid-containing physiological concentrations of various electrolytes returned to the circulation. No benefit in terms of duration of postoperative ventilation or length of intensive care unit stay in adult patients was shown in a recent metaanalysis by Zhu et al. (54). Little evidence of a sustained benefit with regard to lung function has been shown with modified ultrafiltration (MUF) also (55).

Miniaturized extracorporeal circulation (MECC) holds the potential to reduce various inflammatory mediators compared with conventional extracorporeal circuits. In a recent meta-analysis of clinical trials including 24 studies with a total of 2,770 patients (56), the use of MECC in heart surgery resulted in improved short-term outcome as reflected by reduced mortality $(\mathrm{P}=0.02)$, postoperative myocardial infarction $(\mathrm{P}=0.03)$ and neurologic events
$(\mathrm{P}=0.008)$ compared with conventional extracorporeal circulation.

In a large clinical trial involving 1,000 patients with ALI (57), conservative fluid management has shown to improve lung function and shorten the duration of mechanical ventilation and intensive care unit stay without increasing non-pulmonary organ failures, although no significant difference in the primary outcome of 60-day mortality was demonstrated (rate of death at 60 days: $25.5 \%$ in the conservative-strategy group vs. $28.4 \%$ in the liberalstrategy group; $\mathrm{P}=0.30 ; 95 \% \mathrm{CI}$ for the difference, $-2.6 \%$ to $8.4 \%$ ). Conscientious use of diuretics in post cardiac surgery patients remains essential.

Conclusive evidence on the use of corticosteroids in patients with ARDS is currently lacking. While their administration might theoretically attenuate the inflammatory response, no beneficial impact on mortality has been demonstrated (mortality at 180 days $31.9 \%$ vs. $31.5 \%$ in the placebo group vs methylprednisolone group, respectively; $\mathrm{P}=1$ ) (58). Furthermore, late administration after ARDS onset ( $\geq 14$ days) increased the risk of death and is therefore highly discouraged (58). The effect of intraoperative high-dose dexamethasone on the incidence of major adverse events was evaluated in 4,494 patients undergoing cardiac surgery. No reduction in 30-day incidence of major adverse events compared with placebo was demonstrated (59).

In a small prospective, randomized, double-blind, placebo-controlled clinical study enrolling a total of 20 patients, the administration of $\mathrm{N}$-acetylcysteine (NAC) to patients undergoing elective CABG with CPB improved systemic oxygenation. However, there was no effect on other pulmonary parameters or on intubation time (60).

Mechanical ventilation strategies play a central role in both prevention and management of ARDS. High tidal volume ventilation in cardiac surgery patients is associated with the release of inflammatory mediators causing lung injury (61). In a seminal study comparing the use of traditional $12 \mathrm{~mL} / \mathrm{kg} /$ predicted body weight (PBW) tidal volume with $6 \mathrm{~mL} / \mathrm{kg} / \mathrm{PBW}$ in patients with ARDS, mortality was found to be significantly lower in the low tidal volume group (39.8\% vs. $31 \%$, respectively; $\mathrm{P}=0.007$ ) (62). Indeed, low tidal volumes set to PBW should be considered since not only they are effective once ARDS is already established but they are also protective in patients at risk of developing ARDS (63). PEEP and oxygen should be carefully titrated to achieve a $\mathrm{SpO}_{2}>93 \%$ (10). Cardiac surgery-related pulmonary complications include alterations 
in lung mechanics and anomalies in gas exchange. In view of the fact that higher levels of PEEP have been suggested to be beneficial for cardiac surgical patients, Dongelmans et al. (64) compared respiratory compliance, arterial oxygenation and time till tracheal extubation in two cohorts of patients weaned from mechanical ventilation with different levels of PEEP after elective and uncomplicated CABG. The use of higher PEEP levels $\left(10 \mathrm{cmH}_{2} \mathrm{O}\right.$ for the first 4 hours followed by PEEP levels of $5 \mathrm{cmH}_{2} \mathrm{O}$ until tracheal extubation) improved pulmonary compliance and oxygenation compared to lower PEEP level $\left(5 \mathrm{cmH}_{2} \mathrm{O}\right.$ during the entire weaning phase) but this was associated with delayed extubation $[16.9 \pm 6.1$ vs. $10.5 \pm 5.0$ hours $(\mathrm{P}<0.001)]$.

The anesthetic technique significantly impacts on time to extubation, also. Early extubation, generally considered to be that which is performed during the first 6-8 hours once the preoperative homeostatic state has been reestablished (40), offers a substantial advantage in terms of accelerated recovery, shorter intensive care unit and hospital stay, suggesting that efforts to reduce extubation time are cost-effective (65). Cardiac surgical patients in whom low tidal volumes are administered are more likely to undergo early extubation $(37.3 \%$ vs. $20.3 \% ; \mathrm{P}=0.02)$ and less likely to require re-intubation $(1.3 \%$ vs. $9.5 \% ; \mathrm{P}=0.03)(66)$. Safety and efficacy of fast-track care in patients undergoing cardiac surgery was brilliantly assessed by Zhu and colleagues (67) who showed no statistically significant difference in mortality between early and conventional extubation in patients considered to be at low to moderate risk. A total of 421 fast-track cardiac surgery patients were matched successfully to 421 control patients by Ender et al. (68). Fast-track patients showed significantly shorter times to extubation [75 (range, 45-110) vs. $900(600-1,140) \mathrm{min}$ ], as well as shorter lengths of stay in the post-anesthetic or intensive care unit [4 (range, 3.0-5) vs. 20 (range, 16-25) h], intermediate care unit [21 (range, 17-39) vs. 26 (range, 19-49) h], and hospital [10 (range, 8-12) vs. 11 (range, 9-14) days] (expressed as median and interquartile range, all $\mathrm{P}<0.01)$. They also had a lower risk of postoperative low cardiac output syndrome $(0.5 \%$ vs. $2.9 \%, \mathrm{P}<0.05)$ and mortality $(0.5 \%$ vs. $3.3 \%, \mathrm{P}<0.01)$. Details about the "the Leipzig fast-track protocol" have been provided (68).

General measures to reduce the likelihood of developing ventilation-associated pneumonia (VAP) should be widely adopted. The effectiveness of cleansing of the nasopharynx and oropharynx with chlorhexidine in reducing VAP rate has been demonstrated in a large randomized clinical trial (69). Moreover, aspiration of subglottic secretions (70), hand washing, semi-recumbent position and careful optimization of the sedative therapy have been proved to be helpful (71). Prophylactic use of wide spectrum antibiotics is controversial, being a serious matter of concern in that it could have a strong impact on the development of bacterial resistance.

\section{Patient optimization}

Early postoperative mobilization and perioperative physiotherapy may be useful tools aiming at reducing the length of in-hospital stay, decreasing delirium and improving functional mobility (72) but controversial evidence about their efficacy has been provided (73). A systematic review on the effect of preoperative physiotherapy published in 2012 by the Cochrane collaboration analyzed the data of eight randomized controlled trials, including a total of 856 patients for quantitative analysis (74). While in the abovementioned study preoperative physical therapy was shown to significantly reduce postoperative atelectasis ( 4 trials, RR 0.52; 95\% CI: $0.32-0.87 ; \mathrm{P}=0.01$ ), incidence of pneumonia (5 trials, RR $0.45 ; 0.95 \%$ CI: $0.24-0.83 ; \mathrm{P}=0.01$ ), and inhospital stay ( 3 trials, -3.2 days; $95 \%$ CI: -5.73 to 0.69 ; $\mathrm{P}=0.01)$, other authors failed to show any beneficial effects (75). Physiotherapy in the postoperative period may improve the mobilization of secretions and prevent atelectasis from progressing into pneumonia. However, the positive effects of postoperative physical interventions remain unproved (76).

As widely known, smoking is associated with worsening outcomes in cardiac surgery patients and is an independent predictor of pulmonary complications (77). Smoking cessation is therefore highly recommended and its benefits have been demonstrated even when initiated shortly before surgery (78).

\section{Rescue measures}

Preventive strategies to avoid the development of ARDS in cardiac surgery patients should always be sought. Nevertheless, despite clinicians' efforts, patients may progress to more severe forms of this syndrome requiring unconventional measures.

Severe cases of ARDS may benefit from aggressive therapeutic strategies including neuromuscular blockade. In a study (79) involving 340 patients presenting to the intensive care unit with an onset of severe ARDS within 
the previous 48 hours, randomly assigned to receive for 48 hours either cisatracurium besylate or placebo, early administration of the neuromuscular blocking agent improved the adjusted 90-day survival and increased the time off the ventilator without increasing muscle weakness (HR 0.68; 95\% CI: 0.48-0.98; P=0.04).

Non-conventional ventilation strategies may be required in case of refractory, life-threatening ARDS. High frequency oscillatory ventilation $(\mathrm{HFOV})$, in particular, combines high respiratory rate $(3-15 \mathrm{~Hz},>900$ breaths/min) and tidal volumes smaller than anatomical dead space volume, basically maintaining a constant distending mean airway pressure around which the oscillations take place. This strategy results in homogenous distribution of ventilation by maintaining a high mean airway pressure and reduces the risk of ventilator-induced lung injury and hyperinflation (80). Recently, two randomized controlled trials failed to show any mortality benefit with HFOV. The OSCILLATE trial (81), in particular, was stopped early because of higher in-hospital mortality in HFOV group $v s$. the control group ( $47 \%$ vs. $35 \% ; \mathrm{P}=0.005)$. Although no harm was demonstrated in the OSCAR trial (82), no survival benefit was observed with HFOV which is currently not recommended as an initial strategy for ARDS.

Prone ventilation can be defined as delivering mechanical ventilation with patient in prone position. The PROSEVA trial (83) enrolled 466 patients with severe ARDS, subjected to either prone or supine conventional mechanical ventilation. Prone ventilation was associated with a decrease in 28 - and 90 -day mortality $(16 \%$ vs. $33 \% ; \mathrm{P}<0.001$ and $29 \%$ vs. $41 \% ; \mathrm{P}<0.001$, respectively), increased ventilatorfree days and reduced time to extubation. Concerns about positioning patients with a recent sternotomy in prone positions should be acknowledged when dealing with cardiac surgery.

The rationale for improved ventilation-perfusion matching and oxygenation in ARDS patients after inhaled pulmonary vasodilators (nitric oxide, in particular) is based on selective pulmonary vasodilatation in well-ventilated lung units. However, despite the above mentioned favorable effects of the administration of inhaled nitric oxide, a meta-analysis of 12 trials involving 1,237 patients found no significant effect on hospital mortality (RR 1.10; 95\% CI: 0.94-1.30), duration of ventilation, or ventilatorfree days (84).

Extracorporeal membrane oxygenation (ECMO) is a technique consisting in removing blood from the patient, passing it through an artificial lung and sending it back to the patient again. The efficacy of ECMO in patients with severe hypoxemia was tested in the CESAR trial (85) in which patients were randomized to either receiving standard ventilatory strategy (or other rescue modalities) at their original hospital or being referred to a center with known high skills in performing ECMO. Survival at 6 months or the absence of severe disability was reported in $63 \%$ of ECMO patients vs. $47 \%$ of the standard therapy patients $(\mathrm{P}=0.003)$. Nevertheless, the design of the study has been highly criticized mainly because different ventilation protocols were used at different centers. However, ECMO represents a great potential opportunity for treatment in case of life-threatening, refractory hypoxemia, indicated in case of refractory hypoxemia due to a potential reversible cause, $<7$ days of present stay on mechanical ventilation, age $<65$ years, no significant comorbidities, no contraindication to anticoagulation, and no significant neurological dysfunction (80).

\section{Conclusions}

ARDS is a potentially life-threatening complication in patients undergoing cardiac surgery. Efforts should be made in order to identify those at higher risk and provide preventative strategies aimed at decreasing the likelihood of developing this ominous condition and improve survival rates.

\section{Acknowledgements}

None.

\section{Footnote}

Conflicts of Interest: The authors have no conflicts of interest to declare.

\section{References}

1. Ashbaugh DG, Bigelow DB, Petty TL, et al. Acute respiratory distress in adults. Lancet 1967;2:319-23.

2. Rubenfeld GD, Caldwell E, Peabody E, et al. Incidence and outcomes of acute lung injury. N Engl J Med 2005;353:1685-93.

3. Weissman C. Pulmonary complications after cardiac surgery. Semin Cardiothorac Vasc Anesth 2004;8:185-211.

4. Asimakopoulos G, Taylor KM, Smith PL, et al. Prevalence of acute respiratory distress syndrome after cardiac surgery. 
J Thorac Cardiovasc Surg 1999;117:620-1.

5. Fowler AA, Hamman RF, Good JT, et al. Adult respiratory distress syndrome: risk with common predispositions. Ann Intern Med 1983;98:593-7.

6. Gajic O, Dabbagh O, Park PK, et al. Early identification of patients at risk of acute lung injury: evaluation of lung injury prediction score in a multicenter cohort study. Am J Respir Crit Care Med 2011;183:462-70.

7. Kor DJ, Lingineni RK, Gajic O, et al. Predicting risk of postoperative lung injury in high-risk surgical patients: a multicenter cohort study. Anesthesiology 2014;120:1168-81.

8. Messent M, Sullivan K, Keogh BF, et al. Adult respiratory distress syndrome following cardiopulmonary bypass: incidence and prediction. Anaesthesia 1992;47:267-8.

9. Milot J, Perron J, Lacasse $Y$, et al. Incidence and predictors of ARDS after cardiac surgery. Chest 2001;119:884-8.

10. Stephens RS, Shah AS, Whitman GJ. Lung injury and acute respiratory distress syndrome after cardiac surgery. Ann Thorac Surg 2013;95:1122-9.

11. Edwards MB, Taylor KM. A profile of valve replacement surgery in the UK (1986-1997): a study from the UK Heart Valve Registry. J Heart Valve Dis 1999;8:697-701.

12. Nalysnyk L, Fahrbach K, Reynolds MW, et al. Adverse events in coronary artery bypass graft (CABG) trials: a systematic review and analysis. Heart 2003;89:767-72.

13. Bernard GR, Artigas A, Brigham KL, et al. The AmericanEuropean Consensus Conference on ARDS. Definitions, mechanisms, relevant outcomes, and clinical trial coordination. Am J Respir Crit Care Med 1994;149:818-24.

14. Ranieri VM, Rubenfeld GD, Thompson BT, et al. Acute respiratory distress syndrome: the Berlin Definition. JAMA 2012;307:2526-33.

15. Kogan A, Preisman S, Levin S, et al. Adult respiratory distress syndrome following cardiac surgery. J Card Surg 2014;29:41-6.

16. Christenson JT, Aeberhard JM, Badel P, et al. Adult respiratory distress syndrome after cardiac surgery. Cardiovasc Surg 1996;4:15-21.

17. Kaul TK, Fields BL, Riggins LS, et al. Adult respiratory distress syndrome following cardiopulmonary bypass: incidence, prophylaxis and management. J Cardiovasc Surg (Torino) 1998;39:777-81.

18. Chen SW, Chang CH, Chu PH, et al. Risk factor analysis of postoperative acute respiratory distress syndrome in valvular heart surgery. J Crit Care 2016;31:139-43.

19. Naughton PA, Park MS, Morasch MD, et al. Emergent repair of acute thoracic aortic catastrophes: a comparative analysis. Arch Surg 2012;147:243-9.
20. Genovese EA, Dew MA, Teuteberg JJ, et al. Early adverse events as predictors of 1-year mortality during mechanical circulatory support. J Heart Lung Transplant 2010;29:981-8.

21. Kirklin JK, Chenoweth DE, Naftel DC, et al. Effects of protamine administration after cardiopulmonary bypass on complement, blood elements, and the hemodynamic state. Ann Thorac Surg 1986;41:193-9.

22. Sharath MD, Metzger WJ, Richerson HB, et al. Protamine-induced fatal anaphylaxis. Prevalence of antiprotamine immunoglobulin E antibody. J Thorac Cardiovasc Surg 1985;90:86-90.

23. Weiler JM, Freiman P, Sharath MD, et al. Serious adverse reactions to protamine sulfate: are alternatives needed? J Allergy Clin Immunol 1985;75:297-303.

24. Asimakopoulos G, Smith PL, Ratnatunga CP, et al. Lung injury and acute respiratory distress syndrome after cardiopulmonary bypass. Ann Thorac Surg 1999;68:1107-15.

25. Chenoweth DE, Cooper SW, Hugli TE, et al.

Complement activation during cardiopulmonary bypass: evidence for generation of $\mathrm{C} 3 \mathrm{a}$ and $\mathrm{C} 5 \mathrm{a}$ anaphylatoxins. $\mathrm{N}$ Engl J Med 1981;304:497-503.

26. Ohri SK, Bjarnason I, Pathi V, et al. Cardiopulmonary bypass impairs small intestinal transport and increases gut permeability. Ann Thorac Surg 1993;55:1080-6.

27. Baue AE. The role of the gut in the development of multiple organ dysfunction in cardiothoracic patients. Ann Thorac Surg 1993;5 5:822-9.

28. Chen S, Xu L, Tang J. Association of interleukin 18 gene polymorphism with susceptibility to the development of acute lung injury after cardiopulmonary bypass surgery. Tissue Antigens 2010;76:245-9.

29. Wang JF, Bian JJ, Wan XJ, et al. Association between inflammatory genetic polymorphism and acute lung injury after cardiac surgery with cardiopulmonary bypass. Med Sci Monit 2010;16:CR260-5.

30. Koch CG, Li L, Duncan AI, et al. Morbidity and mortality risk associated with red blood cell and blood-component transfusion in isolated coronary artery bypass grafting. Crit Care Med 2006;34:1608-16.

31. Koch CG, Li L, Sessler DI, et al. Duration of red-cell storage and complications after cardiac surgery. N Engl J Med 2008;358:1229-39.

32. Silliman CC, Ambruso DR, Boshkov LK. Transfusionrelated acute lung injury. Blood 2005;105:2266-73.

33. Vlaar AP, Hofstra JJ, Determann RM, et al. The incidence, risk factors, and outcome of transfusion-related acute lung injury in a cohort of cardiac surgery patients: a prospective 
nested case-control study. Blood 2011;117:4218-25.

34. Bux J, Sachs UJ. The pathogenesis of transfusion-related acute lung injury (TRALI). Br J Haematol 2007;136:788-99.

35. Silliman CC. The two-event model of transfusion-related acute lung injury. Crit Care Med 2006;34:S124-31.

36. Vlaar AP, Hofstra JJ, Determann RM, et al. Transfusionrelated acute lung injury in cardiac surgery patients is characterized by pulmonary inflammation and coagulopathy: a prospective nested case-control study. Crit Care Med 2012;40:2813-20.

37. Worthen GS, Schwab B 3rd, Elson EL, et al. Mechanics of stimulated neutrophils: cell stiffening induces retention in capillaries. Science 1989;245:183-6.

38. Kelher MR, Masuno T, Moore EE, et al. Plasma from stored packed red blood cells and MHC class I antibodies causes acute lung injury in a 2 -event in vivo rat model. Blood 2009;113:2079-87.

39. Koch C, Li L, Figueroa P, et al. Transfusion and pulmonary morbidity after cardiac surgery. Ann Thorac Surg 2009;88:1410-8.

40. García-Delgado M, Navarrete-Sánchez I, Colmenero M. Preventing and managing perioperative pulmonary complications following cardiac surgery. Curr Opin Anaesthesiol 2014;27:146-52.

41. Hajjar LA, Vincent JL, Galas FR, et al. Transfusion requirements after cardiac surgery: the TRACS randomized controlled trial. JAMA 2010;304:1559-67.

42. Kochamba GS, Yun KL, Pfeffer TA, et al. Pulmonary abnormalities after coronary arterial bypass grafting operation: cardiopulmonary bypass versus mechanical stabilization. Ann Thorac Surg 2000;69:1466-70.

43. Vedin J, Jensen U, Ericsson A, et al. Pulmonary hemodynamics and gas exchange in off pump coronary artery bypass grafting. Interact Cardiovasc Thorac Surg 2005;4:493-7.

44. Meharwal ZS, Mishra YK, Kohli V, et al. Off-pump multivessel coronary artery surgery in high-risk patients. Ann Thorac Surg 2002;74:S1353-7.

45. Kerendi F, Halkos ME, Puskas JD, et al. Impact of off-pump coronary artery bypass graft surgery on postoperative pulmonary complications in patients with chronic lung disease. Ann Thorac Surg 2011;91:8-15.

46. Møller CH, Perko MJ, Lund JT, et al. No major differences in 30-day outcomes in high-risk patients randomized to off-pump versus on-pump coronary bypass surgery: the best bypass surgery trial. Circulation 2010;121:498-504.

47. Staton GW, Williams WH, Mahoney EM, et al.
Pulmonary outcomes of off-pump vs on-pump coronary artery bypass surgery in a randomized trial. Chest 2005;127:892-901.

48. Oz BS, Iyem H, Akay HT, et al. Preservation of pleural integrity during coronary artery bypass surgery affects respiratory functions and postoperative pain: a prospective study. Can Respir J 2006;13:145-9.

49. Ubben JF, Lance MD, Buhre WF, et al. Clinical strategies to prevent pulmonary complications in cardiac surgery: an overview. J Cardiothorac Vasc Anesth 2015;29:481-90.

50. Kristjánsdóttir A, Ragnarsdóttir $M$, Hannesson $\mathrm{P}$, et al. Chest wall motion and pulmonary function are more diminished following cardiac surgery when the internal mammary artery retractor is used. Scand Cardiovasc J 2004;38:369-74.

51. Damgaard S, Nielsen CH, Andersen LW, et al. Cell saver for on-pump coronary operations reduces systemic inflammatory markers: a randomized trial. Ann Thorac Surg 2010;89:1511-7.

52. Warren O, Alexiou C, Massey R, et al. The effects of various leukocyte filtration strategies in cardiac surgery. Eur J Cardiothorac Surg 2007;31:665-76.

53. Young RW. Prevention of lung injury in cardiac surgery: a review. J Extra Corpor Technol 2014;46:130-41.

54. Zhu X, Ji B, Wang G, et al. The effects of zerobalance ultrafiltration on postoperative recovery after cardiopulmonary bypass: a meta-analysis of randomized controlled trials. Perfusion 2012;27:386-92.

55. Luciani GB, Menon T, Vecchi B, et al. Modified ultrafiltration reduces morbidity after adult cardiac operations: a prospective, randomized clinical trial. Circulation 2001;104:I253-9.

56. Anastasiadis K, Antonitsis P, Haidich AB, et al. Use of minimal extracorporeal circulation improves outcome after heart surgery; a systematic review and meta-analysis of randomized controlled trials. Int J Cardiol 2013;164:158-69.

57. Wiedemann HP, Wheeler AP, Bernard GR, et al. Comparison of two fluid-management strategies in acute lung injury. N Engl J Med 2006;354:2564-75.

58. Steinberg KP, Hudson LD, Goodman RB, et al. Efficacy and safety of corticosteroids for persistent acute respiratory distress syndrome. N Engl J Med 2006;354:1671-84.

59. Dieleman JM, Nierich AP, Rosseel PM, et al. Intraoperative high-dose dexamethasone for cardiac surgery: a randomized controlled trial. JAMA 2012;308:1761-7.

60. Eren N, Cakir O, Oruc A, et al. Effects of N-acetylcysteine on pulmonary function in patients undergoing coronary 
artery bypass surgery with cardiopulmonary bypass. Perfusion 2003;18:345-50.

61. Zupancich E, Paparella D, Turani F, et al. Mechanical ventilation affects inflammatory mediators in patients undergoing cardiopulmonary bypass for cardiac surgery: a randomized clinical trial. J Thorac Cardiovasc Surg 2005;130:378-83.

62. Ventilation with lower tidal volumes as compared with traditional tidal volumes for acute lung injury and the acute respiratory distress syndrome. The Acute Respiratory Distress Syndrome Network. N Engl J Med 2000;342:1301-8.

63. Webb HH, Tierney DF. Experimental pulmonary edema due to intermittent positive pressure ventilation with high inflation pressures. Protection by positive end-expiratory pressure. Am Rev Respir Dis 1974;110:556-65.

64. Dongelmans DA, Hemmes SN, Kudoga AC, et al. Positive end-expiratory pressure following coronary artery bypass grafting. Minerva Anestesiol 2012;78:790-800.

65. Rashid A, Sattar KA, Dar MI, et al. Analyzing the outcome of early versus prolonged extubation following cardiac surgery. Ann Thorac Cardiovasc Surg 2008;14:218-23.

66. Sundar S, Novack V, Jervis K, et al. Influence of low tidal volume ventilation on time to extubation in cardiac surgical patients. Anesthesiology 2011;114:1102-10.

67. Zhu F, Lee A, Chee YE. Fast-track cardiac care for adult cardiac surgical patients. Cochrane Database Syst Rev 2012;10:CD003587.

68. Ender J, Borger MA, Scholz M, et al. Cardiac surgery fasttrack treatment in a postanesthetic care unit: six-month results of the Leipzig fast-track concept. Anesthesiology 2008;109:61-6.

69. Segers P, Speekenbrink RG, Ubbink DT, et al. Prevention of nosocomial infection in cardiac surgery by decontamination of the nasopharynx and oropharynx with chlorhexidine gluconate: a randomized controlled trial. JAMA 2006;296:2460-6.

70. Bouza E, Perez MJ, Munoz P, et al. Continuous aspiration of subglottic secretions in the prevention of ventilatorassociated pneumonia in the postoperative period of major heart surgery. Chest 2008;134:938-46.

71. Rello J, Afonso E, Lisboa T, et al. A care bundle approach for prevention of ventilator-associated pneumonia. Clin Microbiol Infect 2013;19:363-9.

72. Needham DM, Korupolu R, Zanni JM, et al. Early physical medicine and rehabilitation for patients with acute respiratory failure: a quality improvement project. Arch
Phys Med Rehabil 2010;91:536-42.

73. Makhabah DN, Martino F, Ambrosino N. Peri-operative physiotherapy. Multidiscip Respir Med 2013;8:4.

74. Hulzebos EH, Smit Y, Helders PP, et al. Preoperative physical therapy for elective cardiac surgery patients. Cochrane Database Syst Rev 2012;11:CD010118.

75. Valkenet K, de Heer F, Backx FJ, et al. Effect of inspiratory muscle training before cardiac surgery in routine care. Phys Ther 2013;93:611-9.

76. Pasquina P, Tramer MR, Walder B. Prophylactic respiratory physiotherapy after cardiac surgery: systematic review. BMJ 2003;327:1379.

77. Al-Sarraf N, Thalib L, Hughes A, et al. Effect of smoking on short-term outcome of patients undergoing coronary artery bypass surgery. Ann Thorac Surg 2008;86:517-23.

78. Myers K, Hajek P, Hinds C, et al. Stopping smoking shortly before surgery and postoperative complications: a systematic review and meta-analysis. Arch Intern Med 2011;171:983-9.

79. Papazian L, Forel JM, Gacouin A, et al. Neuromuscular blockers in early acute respiratory distress syndrome. $\mathrm{N}$ Engl J Med 2010;363:1107-16.

80. Mehta C, Mehta Y. Management of refractory hypoxemia. Ann Card Anaesth 2016;19:89-96.

81. Ferguson ND, Cook DJ, Guyatt GH, et al. Highfrequency oscillation in early acute respiratory distress syndrome. N Engl J Med 2013;368:795-805.

82. Young D, Lamb SE, Shah S, et al. High-frequency oscillation for acute respiratory distress syndrome. N Engl J Med 2013;368:806-13.

83. Guérin C, Reignier J, Richard JC, et al. Prone positioning in severe acute respiratory distress syndrome. N Engl J Med 2013;368:2159-68.

84. Adhikari NK, Burns KE, Friedrich JO, et al. Effect of nitric oxide on oxygenation and mortality in acute lung injury: systematic review and meta-analysis. BMJ 2007;334:779.

85. Peek GJ, Mugford M, Tiruvoipati R, et al. Efficacy and economic assessment of conventional ventilatory support versus extracorporeal membrane oxygenation for severe adult respiratory failure (CESAR): a multicentre randomised controlled trial. Lancet 2009;374:1351-63.

Cite this article as: Rong LQ, Di Franco A, Gaudino M. Acute respiratory distress syndrome after cardiac surgery. J Thorac Dis 2016;8(10):E1177-E1186. doi: 10.21037/jtd.2016.10.74 